\title{
THE EFFECT OF ALCOHOL PROHIBITION ON ALCOHOL CONSUMPTION
}

\author{
Jeffrey A. Miron \\ Working Paper 7130 \\ http://www.nber.org/papers/w7130 \\ NATIONAL BUREAU OF ECONOMIC RESEARCH \\ 1050 Massachusetts Avenue \\ Cambridge, MA 02138 \\ May 1999
}

I thank Dan Ackerberg, Frank Chaloupka, Russ Cooper, Stratford Douglas, Simon Gilchrist, Patrick Rey, Robert Rosenthal, Mark Thornton, Jean Tirole, and Andy Weiss for useful comments, and Jack Blocker for help in finding data. The views expressed herein are those of the authors and do not necessarily reflect the views of the National Bureau of Economic Research.

(1) 1999 by Jeffrey A. Miron. All rights reserved. Short sections of text, not to exceed two paragraphs, may be quoted without explicit permission provided that full credit, including ${ }^{\circledR}$ notice, is given to the source. 
The Effect of Alcohol Prohibition on Alcohol Consumption

Jeffrey A. Miron

NBER Working Paper No. 7130

May 1999

JEL No. I1, J1, K4, N4

\begin{abstract}
This paper examines the impact of Prohibition on alcohol consumption. Since data on both the price and quantity of alcohol are unavailable during the Prohibition period, it is not possible to estimate Prohibition's impact on either the supply or demand for alcohol. Assuming the existence of a reasonable proxy for alcohol consumption, however, it is possible to estimate the net impact of Prohibition on the equilibrium quantity of alcohol consumed. I estimate this effect under a range of assumptions about the nature of preferences, taking into account other possible determinants of alcohol consumption and the proxy series. The overall conclusion of the paper is that Prohibition exerted a modest and possibly even a positive effect on alcohol consumption.

One possible interpretation of the results is that the demand for alcohol is relatively inelastic, although many earlier studies find substantial elasticity in the demand for alcohol. Another possible interpretation is that Prohibition created a forbidden fruit effect that increased preferences for alcohol, tending to offset the depressing effects of increased prices on demand. Still a third possibility is that Prohibition failed to raise alcohol prices substantially, perhaps because black markets suppliers face low marginal costs of evading government regulations and taxes. Existing data provide some support for this last possibility.
\end{abstract}

Jeffrey A. Miron

270 Bay State Road

Department of Economics

Boston University

Boston, MA 02215

and NBER

jmiron@bu.edu 
I never drank so much in my life as the time I spent five months in the United States during Prohibition. Luis Buñuel, My Last Sigh, 1982.

\section{Introduction}

The U.S. experience with Alcohol Prohibition plays a frequent role in public policy debates about prohibitions of alcohol, drugs and other commodities. Advocates of government prohibitions often cite Alcohol Prohibition as evidence that prohibitions are effective in reducing consumption of the prohibited good, typically citing the large drop in cirrhosis death rates from the pre-Prohibition to the early Prohibition period in support of this claim. At the same time, opponents of government prohibitions frequently cite Alcohol Prohibition as evidence that such prohibitions are not effective in reducing consumption, typically citing the small change in cirrhosis death rates from the late Prohibition to the post-Prohibition period in support of this claim. Prima facie, both sets of claims about Alcohol Prohibition have merit, but neither controls for the range of other factors that might determine alcohol consumption or cirrhosis death rates. Thus, both set of claims require further scrutiny.

This paper examines the impact of Prohibition on alcohol consumption, taking into account a broad range of other possible determinants of that consumption. Warburton (1932) and Miron and Zwiebel (1991) estimate alcohol consumption for the Prohibition years, but they do not determine to what extent factors other than Prohibition contributed to observed fluctuations in consumption. The analysis here attempts to isolate the effect of Prohibition on alcohol consumption, controlling for other relevant effects. The conclusion offered below is that Prohibition had virtually no effect on alcohol consumption.

Section 2 provides the basic theoretical framework employed in the paper. Since data on both the price and quantity of alcohol are unavailable during the Prohibition period, it is not possible to recover structural estimates of Prohibition's impact on either the supply or demand for alcohol. Assuming the existence of a reasonable proxy for alcohol consumption, however, it is possible to estimate the net impact of Prohibition on the equilibrium quantity of alcohol consumed. I discuss estimation of this effect under a range of assumptions about the demand for alcohol, including both myopic and rationally addictive models of consumption. 
Section 3 examines the relation between alcohol consumption and the proxy series considered in this paper, the death rate from cirrhosis. An extensive medical literature documents the crucial role of alcohol consumption in producing cirrhosis, and a substantial earlier literature uses cirrhosis as a proxy for true alcohol consumption (e.g., Cook (1981), Cook and Tauchen (1982), Chaloupka, Grossman, Becker and Murphy (1993)). Cirrhosis is probably better correlated with heavy alcohol consumption than with casual consumption, but heavy consumption accounts for much of total consumption and is more relevant to policy questions in many cases.

The evidence presented here shows there has been a strong relation between alcohol consumption and cirrhosis during most of the period for which data on both series are available. This does not necessarily validate the use of cirrhosis to measure alcohol consumption during Prohibition, since Prohibition might have altered the relation between alcohol consumption and cirrhosis. Evidence provided in Miron and Zwiebel (1991), however, suggests that of the available proxies, cirrhosis makes the best case for the efficacy of Prohibition. Moreover, at least one plausible kind of bias - the underdiagnosis of cirrhosis because of stigma attached to alcohol consumption - implies that the conclusions provided below are, if anything, understated. And in any event, cirrhosis is the proxy used to support most existing claims about Prohibition's effect on alcohol consumption, so it makes sense to examine cirrhosis despite any limitations.

Section 4 evaluates the impact of Prohibition on the cirrhosis death rate, taking into account other possible determinants of both cirrhosis and alcohol consumption. One key determinant is the age structure of the population, which turns out to play a crucial role in understanding the impact of Prohibition on the consumption of alcohol. Another important determinant is lagged values of cirrhosis and alcohol consumption, as implied by the Becker and Murphy (1988) model of rational addiction and by the dynamics of the relation between alcohol consumption and cirrhosis. The third critical factor is World War I, which reduced alcohol consumption and cirrhosis through a variety of mechanisms. The analysis also accounts for the effects of alcoholic beverage taxes, state prohibition laws, drug prohibition, and the varying enforcement of constitutional prohibition. These factors play some role, but they do not change the conclusions suggested by the more parsimonious specifications that account simply for age effects, lags, and WWI. That conclusion is that Prohibition exerted a modest and possibly even a small positive effect on the consumption of alcohol.

Section 5 concludes by discussing possible interpretations of the results, 
specifically the small and possibly positive effect of Prohibition on alcohol consumption. One possibility is that the demand for alcohol is relatively inelastic, but many earlier studies find substantial elasticity in the demand for alcohol. A second possibility is that Prohibition created a forbidden fruit effect, increasing preferences for alcohol and offsetting the depressing effects on demand of increased prices. This possibility is intriguing, and anecdotal evidence suggests it played a role, but this paper offers no concrete evidence in that direction other than the fact that alcohol consumption failed to decline.

The remaining potential explanation for the paper's key result is that Prohibition failed to increase alcohol prices substantially because black market suppliers faced low marginal costs of evading goverment regulation and taxes. The existing wisdom, based chiefly on Warburton (1932) and Fisher $(1928,1930)$, is that Prohibition raised alcohol prices markedly, but further examination of this evidence shows that prices did not necessarily rise by much and may even have declined. Thus, there is not necessarily a huge surprise in the modest response of alcohol consumption to Prohibition.

\section{Framework for Analysis}

This section presents a framework in which to analyze the effects of Prohibition on alcohol consumption. The framework consists essentially of demand and supply curves for alcohol consumption, augmented by the relation between true alcohol consumption and a proxy for that consumption. The estimation strategy proposed cannot disentangle the structural parameters of the model, but it can determine the reduced form impact of Prohibition on alcohol consumption. Assuming Prohibition can be taken as exogenous, this is an interesting effect to estimate.

\subsection{Alcohol Demand and Supply}

The basic theoretical structure is the Becker and Murphy (1988) model of rationally addictive consumption. Assume the consumer solves

$$
\begin{gathered}
\max \sum_{i=0}^{\infty} \beta^{i} u\left(a_{t+i}, s_{t+i}, y_{t+i}\right) \\
\text { s.t. } \sum_{i=0}^{\infty}(1 /(1+r))^{i}\left(p_{t+i} a_{t+i}+y_{t+i}\right) \leq w_{0} \\
s_{t}=(1-\delta) s_{t-1}+a_{t},
\end{gathered}
$$


where $a_{t}$ is alcohol consumption, $s_{t}$ is the stock of past alcohol consumption, $\delta$ is the depreciation rate of that stock, $y_{t}$ is a vector of other consumption goods, $p_{t}$ is the relative price of alcohol, $r$ is the real interest rate, and $w_{0}$ is initial wealth. ${ }^{1}$

The first-order conditions for this problem are

$$
u_{y}=\lambda
$$

and

$$
u_{a}+\Sigma_{i=0}^{\infty} \beta^{i}(1-\delta)^{i} u_{s}=\lambda p_{t},
$$

where $\lambda$ is the Lagrange multiplier on the wealth constraint. To make this model empirically tractable, I follow Becker, Grossman and Murphy (1994) and especially Chaloupka (1991) in assuming that $u(\cdot)$ is quadratic,

$$
\begin{gathered}
u(\cdot)=\gamma_{a} a_{t}+\gamma_{s} s_{t}+\gamma_{y} y_{t}+(1 / 2) \gamma_{a a} a_{t}^{2}+(1 / 2) \gamma_{s s} s_{t}^{2}+(1 / 2) \gamma_{y y} y_{t}^{2} \\
+\gamma_{a s} a_{t} s_{t}+\gamma_{a y} a_{t} y_{t}+\gamma_{s y} s_{t} y_{t} .
\end{gathered}
$$

Imposing (6), substituting out for $y_{t}$ from (4), and rearranging yields

$$
a_{t}=\phi_{0}+\phi_{1} p_{t-1}+\phi_{2} p_{t}+\phi_{3} p_{t+1}+\phi_{4} a_{t-1}+\phi_{5} a_{t+1}
$$

where $\phi_{2}$ is negative and $\phi_{1}, \phi_{3}, \phi_{4}$ and $\phi_{5}$ are positive. This equation yields a stable solution for $a_{t}$ under appropriate conditions on the roots of the characteristic equation.

Two special cases of this model are worth noting. If consumers are myopic, meaning they set the discount rate equal to infinity, then the future price and consumption terms drop out of equation (7). If alcohol consumption is not addictive, then all terms other than current price drop out. The empirical work below considers all three variants of the model.

The specification described so far does not allow for any direct effect of Prohibition on the demand for alcohol; instead, it assumes that any direct effect is on the cost of producing or selling alcohol, which is then transmitted to demand through price. This assumption is a useful benchmark, but there are several mechanisms through which Prohibition might affect demand directly. On the one hand, Prohibition might stigmatize alcohol consumption,

\footnotetext{
${ }^{1}$ This specification of the consumer's problem ignores any uncertainty about future prices or income, which simplifies the presentation. Under the assumption of quadratic preferences, which is imposed throughout, the derivations below hold as an approximation even when uncertainty is permitted. In the next subsection, I discuss estimation procedures that are robust to the presence of uncertainty.
} 
increase uncertainty about quality, or decrease the availability of alcohol holding the monetary price constant; each of these effects would lower demand for any given monetary price. Alternatively, Prohibition might create a forbidden fruit effect, which would tend to raise consumption for any given monetary price. Thus, the total effect of Prohibition on demand is ambiguous but probably negative overall.

The simplest way to incorporate any effects of Prohibition on the demand for alcohol is to make the intercept term in the marginal utility of alcohol consumption schedule depend on Prohibition:

$$
u_{a}=\gamma_{P} P_{t}+\gamma_{a}+\gamma_{a a} a_{t}+\gamma_{a s} s_{t}+\gamma_{a y} y_{t},
$$

where $P_{t}$ is a measure of Prohibition. With this modification, equation (7) becomes

$$
\begin{aligned}
a_{t}= & \phi_{0}+\phi_{1} p_{t-1}+\phi_{2} p_{t}+\phi_{3} p_{t+1}+\phi_{4} a_{t-1}+\phi_{5} a_{t+1}+ \\
& +\phi_{6} P_{t+1}+\phi_{7} P_{t}+\phi_{8} P_{t-1} .
\end{aligned}
$$

In this specification, $\phi_{6}$ and $\phi_{8}$ are positive, while $\phi_{7}$ is negative, assuming the effect of Prohibition on the marginal utility of alcohol consumption is negative. Thus, Prohibition acts like a component of price.

To close the model, I assume that the market for alcohol is perfectly competitive, so

$$
p_{t}=\theta P_{t}+\epsilon_{t},
$$

where $\epsilon_{t}$ is the marginal cost of producing alcohol in the absence of Prohibition and $\theta P_{t}$ is the effect of Prohibition on the marginal cost of producing alcohol. ${ }^{2}$ The non-Prohibition component of marginal cost includes both marginal production costs, such as materials, capital and labor costs, and government policies other than prohibition that affect marginal costs, such as alcoholic beverage taxes.

The usual presumption is that Prohibition raises the marginal cost of supplying alcohol, so that $\theta$ is positive in (10). Marginal production, distribution and transportation costs are higher under Prohibition because suppliers must evade detection by police and other law enforcement authorities. Marginal labor costs are higher under Prohibition to the extent there is stigma attached to working in a prohibited industry. On the other hand,

\footnotetext{
${ }^{2}$ Miron and Zwiebel (1995) suggest that government prohibitions tend to increase market power in the supply of the prohibited commodity. This implies that the supply of alcohol may have been less competitive during Prohibition than otherwise.
} 
the marginal costs of evading government regulations other than Prohibition are likely to be lower for alcohol suppliers under Prohibition, as are the marginal costs of evading income or excise taxes. Further, black market suppliers may well spend less on adverstising than legal market suppliers, which can then permit lower prices (Motta, 1997). Many of these offsetting effects were probably smaller during Alcohol Prohibition than they would be now, since government regulation was relatively modest and marginal income tax rates were low. Nevertheless, the net effect of Prohibition on price was not necessarily large and possibly not even positive.

\section{$2.2 \quad$ Estimation of the Model}

If data on the quantity and price of alcohol were available both during and outside of the Prohibition period, estimation of Prohibition's impact on alcohol consumption would be straightforward. OLS estimation of (10) would yield consistent estimates of Prohibition's effect on the price of alcohol, and IV estimation of (9) would yield consistent estimates of the relation between the quantity of alcohol consumed and the price. Solving (9) for the long run effect of price on consumption and then using the implied change in price due to Prohibition would then provide an estimate of Prohibition's net effect on alcohol consumption.

Unfortunately, price data are not available for much of the relevant sample period, and alcohol consumption data are not available during Prohibition. I therefore adopt a different strategy for estimating the impact of Prohibition on alcohol consumption.

To avoid the need for price data, I substitute (10) into (9) to get

$$
\begin{aligned}
a_{t}= & \phi_{0}+\left(\phi_{1}+\phi_{6}\right) P_{t-1}+\left(\phi_{2}+\phi_{7}\right) P_{t}+\left(\phi_{3}+\phi_{8}\right) P_{t+1} \\
& +\phi_{4} a_{t-1}+\phi_{5} a_{t+1}+\phi_{1} \epsilon_{t-1}+\phi_{2} \epsilon_{t}+\phi_{3} \epsilon_{t+1} .
\end{aligned}
$$

This equation is a reduced form relating alcohol consumption to Prohibition and the other determinants of marginal cost. I discuss specifications for the marginal cost term further below. Given a particular specification, (11) would be estimable if data on alcohol consumption were available both during and outside of the Prohibition period.

Data on alcohol consumption are not available during Prohibition, how-

ever. To address this problem, I assume the existence of a proxy series that is related to alcohol consumption by

$$
c_{t}=\rho(L)\left(\gamma a_{t}+\eta_{t}\right)
$$


where $c_{t}$ is the proxy series, $\rho(L)$ is a polynomial in the lag operator, and $\eta_{t}$ is a vector of exogenous determinants of $c_{t}$. This specification allows alcohol consumption to affect the proxy series with a lag, which is likely the case, e.g., for cirrhosis. For tractability I assume throughout that

$$
\rho(L)=\Sigma_{i=0}^{\infty} \rho^{i} L^{i}
$$

so (12) can be written as

$$
c_{t}=\rho c_{t-1}+\gamma a_{t}+\eta_{t}
$$

The term $\eta_{t}$ will have positive mean if the proxy can occur even when alcohol consumption is zero (which is the case for cirrhosis), and it will contain a trend if there has been systematic drift in the relation between alcohol consumption and the proxy (e.g., in the ability to treat or diagnosis cirrhosis). Another possibility, considered further below, is that $\eta_{t}$ includes information on the demographic structure of the population, since the effect of any given quantity of alcohol consumption is likely to depend on the age and sex of those doing the consuming.

Solving (14) for $a_{t}$, substituting into (11), and rearranging produces the main estimation equation employed in this paper,

$$
\begin{aligned}
c_{t}= & \alpha_{0}+\alpha_{1} c_{t-1}+\alpha_{2} c_{t-2}+\alpha_{3} c_{t-3}+\alpha_{4} P_{t}+\alpha_{5} P_{t-1}+\alpha_{6} P_{t-2} \\
& +\alpha_{7} \epsilon_{t}+\alpha_{8} \epsilon_{t-1}+\alpha_{9} \epsilon_{t-2}+\alpha_{10} \eta_{t}+\alpha_{11} \eta_{t-1}+\alpha_{12} \eta_{t-2} .
\end{aligned}
$$

This equation relates the proxy series, $c_{t}$, to its own lags, current and lagged values of the Prohibition variable, current and lagged values of nonProhibition marginal costs, and current and lagged values of any exogenous determinants of the proxy series. The first and second lags are implied by the rationally addictive structure of the preferences allowed above, while the third lag of the proxy series is implied by the lag in the effect of alcohol on the proxy.

I employ two different estimation strategies. The first maintains the assumption of no uncertainty in the consumer's problem and imposes that the non-Prohibition component of marginal cost is solely a function of observable variables (specifically, a constant and a time trend). These assumptions imply that one can estimate the equation consistently by OLS, although they also imply that such estimation yields an $R^{2}$ of 1.00. The second approach allows for uncertainty in the consumer's problem and for an unobservable component of marginal cost. The uncertainty facing the consumer 
introduces a second-order moving average error, as does the unobservable component of marginal cost when this component is serially uncorrelated. Under these assumptions, the third, fourth and fifth lags of cirrhosis are valid instruments for the included lags of cirrhosis, so the equation can be consistently estimated by IV. If the unobservable component of marginal cost is serially correlated up to any finite number of lags, IV estimation of the equation is still possible but increasingly problematic because the correlation between the instruments and the regressors is likely to be weak. I thus consider only OLS estimates and IV estimates that assume zero autocorrelation in the unobservable component of marginal cost.

In addition to estimating (15), I also consider the myopic and nonaddictive versions of the model. If consumers are myopic, then $\alpha_{3}=\alpha_{6}=$ $\alpha_{9}=\alpha_{12}=0$. If alcohol consumption is non-addictive, then in addition $\alpha_{2}=\alpha_{5}=\alpha_{8}=\alpha_{11}=0$. These special cases are interesting partly because they can be compared with earlier results in the literature and partly because they conserve degrees of freedom in the estimation.

Given consistent estimates of (15), the net effect of Prohibition on alcohol consumption can be computed as

$$
d a / d P=\left(\alpha_{4}+\alpha_{5}+\alpha_{6}\right) /\left(1-\alpha_{1}-\alpha_{2}-\alpha_{3}\right) .
$$

This estimate is a function of both supply and demand curve parameters, so it does not separately identify Prohibition's effects on the supply or demand for alcohol. The approach is nevertheless interesting, since for many questions it is the total effect of Prohibition that is relevant. In addition, as noted above, demand side effects might be small relative to the supply side effects, in which case the net effect can be interpreted as coming from supply side mechanisms.

The approach outlined above relies on two key identifying assumptions. The first is that the relation between alcohol consumption and the proxy was not affected by the existence of Prohibition, and the second is that the existence of Prohibition was not itself a function of alcohol consumption. Section 3 includes a defense of the first assumption while Section 4 contains a defense of the second. Naturally, it is impossible to prove that either assumption is valid, but I show that under plausible conditions the bias is either small or likely to reinforce the main conclusions reported below. 


\section{The Relation Between Alcohol Consumption and Cirrhosis}

This section documents that the proxy series considered in this paper, the death rate from cirrhosis of the liver, is strongly related to alcohol consumption per capita during most of the non-Prohibition period. This evidence cannot prove that the relation remained unchanged during Prohibition, but combined with the extensive bio-medical and other evidence that alcohol consumption causes most cirrhosis (e.g., Berkow (1992), pp.890-897), this evidence makes a strong case for using the cirrhosis death rate as a proxy for alcohol consumption. In addition, the effect of Prohibition on cirrhosis is interesting even if cirrhosis is not a perfect indicator of alcohol consumption. For example, cirrhosis might be more reflective of heavy drinking than casual drinking, but it is heavy drinking that is the principal concern of public policies toward alcohol consumption.

Figures 1 and 2 present data on alcohol consumption and cirrhosis, respectively. ${ }^{3}$ The data on alcohol consumption are estimates of the per capita consumption of pure alcohol, measured in gallons. These estimates are computed as a weighted sum of separate estimates for beer, spirits, and wine, assuming pure alcohol contents for each component of 0.045, 0.5, and 0.14, respectively. As discussed in detail by Blocker (1994), the pure alcohol content of spirits is difficult to pin down precisely, but this problem is unlikely to be critical for the main issues addressed here.

Comparison of the two figures suggests a correlation between alcohol consumption and cirrhosis. Both series decline noticeably just before the onset of Prohibition and increase gradually for the first three decades after repeal of Prohibition. Both series then increase more rapidly from the mid-1960's to the mid-1970's and decline from 1980 to the present. The correlation is obviously not perfect; alcohol consumption exhibits a noticeable

\footnotetext{
${ }^{3}$ The alcohol consumption data are based on those reported in Miron (1996), with the following modifications. For the period 1900-1919, I use beer1, spirits1, and wine1. For the period 1934-1963, I use beer2, spirits2, and wine2. For the period 1964-1993, I use data on beer, spirits and wine as reported in Food Consumption, Prices, and Expenditures, various issues, published by the Department of Agriculture. These data are the basis of series5 and series6 reported in Miron (1996), but the underlying document contains data on a per capita basis using the resident population, consistent with series1 and series2. The cirrhosis data are from Vital Statistics of the United States, as reported in Historical Statistics of the United States and various Statistical Abtracts. Both the alcohol consumption series and the cirrhosis series use the resident population, all ages, to create per capita estimates and include data on Alaska and Hawaii beginning in 1960.
} 
spike relative to cirrhosis in the 1940's, and cirrhosis starts declining several years earlier than alcohol consumption during the 1970's. Nevertheless, the overall correlation appears strongly positive.

Table 1 confirms this conclusion by reporting estimates of equation (14) under a range of auxilliary assumptions. All regressions include a constant and a time trend in addition to alcohol consumption and/or the lagged value of cirrhosis. The sample period is 1900-1993, minus the years of constitutional prohibition (1920-1933). The t-statistics have been computed using Newey and West (1987) standard errors. The regressions reported in columns (1)-(3) include only the variables listed in the table. Those reported in columns (4)-(6) also include the fraction of the population in the age groups 5-14, 15-24, .., 55-64, and 65 and over. The line of the table labeled "Age Effects" gives the marginal significance level for the test of the exclusion of these age variables.

The justification for this particular way of controlling for age effects is essentially pragmatic: it is linear in easily measured variables, and these variables arise naturally as the appropriate age controls in the alcohol demand equation (see below). Any specification derived rigorously from microeconomic foundations would be non-linear, and non-linearities are unlikely to be well-estimated given the limited number of observations available here. If individual level data on consumption and cirrhosis were available, such data might support a more detailed analysis of this relation, but such an investigation is outside the scope of this paper.

The results in Table 1 show that alcohol consumption is a statistically significant and quantitatively important determinant of cirrhosis and that the age structure of the population plays a critical role in mediating this relation. When lagged cirrhosis and the age variables are excluded from the regression (column (1)), alcohol consumption enters statistically significantly and has a substantial effect on cirrhosis. When lagged cirrhosis is included in the regression and the age variables are excluded, however, the estimated effect of alcohol consumption is not only statistically insignificant but the wrong sign (column (3)). This anomalous result disappears once the age structure variables are included, as shown in columns (4) and (6). In this case alcohol consumption is significant, with the correct sign, and has a substantial effect on cirrhosis. ${ }^{4}$

\footnotetext{
${ }^{4}$ I obtain generally similar results when I estimate the specifications in Table 1 for three sub-periods (1900-1919, 1934-1963, 1964-1993) in which time potential time-consistency problems in the alcohol consumption data are absent; see Appendix Tables 1a-1c. I also obtain generally similar results when I use data on beer or spirits consumption rather than
} 
The magnitude of the estimated effect in Table 1 is substantial. According to the estimates in column (6), for example, an increase in pure alcohol consumption from the range 1.0-1.5 gallons per capita to the range 2.0-2.5 gallons per capita should be associated with an increase in the cirrhosis death rate from the range of 8.0-10.0 deaths per 100,000 to the range 13.0-15.0 deaths per 100,000; in fact, this is almost precisely what occured between the first and second halves of the post-WWII period, as can be seen in Figures 1-2 above.

This evidence makes a strong case for using cirrhosis as a proxy for alcohol consumption, but it does not prove that the relation between cirrhosis and alcohol consumption remained unchanged during Prohibition. The most obvious possibility is that Prohibition stigmatized alcohol consumption and caused medical officials to underreport deaths from cirrhosis. If this is the main source of any change in the relation, then estimates of Prohibition's effects on cirrhosis tend to overstate Prohibition's true effect on alcohol consumption. Moreover, Miron and Zwiebel (1991) document that three other proxies for alcohol consumption - the death rate from alcoholism, the number of admittances to mental hospitals for alcohol psychosis, and the arrest rate for drunkenness - all show smaller declines during most of Prohibition than cirrhosis. Each of these proxies might also be biased; indeed, some might suffer the same "stigmatization" bias as cirrhosis death rates. The fact that cirrhosis shows the largest decline, however, suggests at a minimum that this proxy is the one most likely to show a large effect of Prohibition on alcohol consumption.

\section{The Effect of Prohibition on Cirrhosis}

I turn now to estimating the effect of Prohibition on cirrhosis. I begin with the simplest possible specification and then introduce other factors that might be empirically relevant determinants of cirrhosis. Most of these other factors have little impact on the results, but three - the age structure of the population, the lags implied by rationality and addictiveness, and World War I - play key roles in mediating the relation between Prohibition and cirrhosis.

on total alcohol consumption; see Appendix Tables 1d-1f. The similarity of the beer and spirits results with those based on total alcohol suggests that inconsistencies related to the "proof-gallon puzzle" (Blocker, 1994) are not a major problem for the analysis here. 


\subsection{Baseline Specification}

Table 2 presents estimates of equation (15) under a variety of assumptions. All specifications assume that Prohibition can be modeled as a dummy variable that is one in the years of constitutional prohibition (1920-1933) and zero otherwise. Columns (1)-(4) report OLS estimates and assume that the marginal cost of producing alcohol can be modeled as a constant plus a time trend; columns (5)-(6) report IV estimates that allow for a serially uncorrelated shock to marginal cost and for uncertainty. ${ }^{5}$ Column (1) imposes both that preferences are non-addictive and that the effect of alcohol on cirrhosis is entirely contemporaneous. Column (2) imposes non-addictiveness but allows for lagged effects of alcohol consumption on cirrhosis. Columns (3) and (5) allow alcohol consumption to be addictive but impose that preferences are myopic. Columns (4) and (6) allow for addictiveness and rationality of preferences. The sample period is 1900-1993, minus any years necessary to accommodate the lag structure in each specification. Newey and West (1987) t-statistics are reported in parentheses. The lines labeled "Impact of Prohibition" give the estimated reduced-form impact of the Prohibition dummy on cirrhosis (equation (16) above), along with the marginal significance level from the test of the hypothesis that this effect is zero.

The results in column (1) show that the cirrhosis death rate was indeed lower during Prohibition than before or after. According to the estimates, cirrhosis was lower by 4.29 deaths per year per 100,000 population, which is more than a third of its average non-Prohibition value. This is the fact that supports claims of a substantial role for Prohibition in reducing alcohol consumption; the fact is apparent from inspection of Figure 2. This fact does not demonstrate that Prohibition caused consumption to be lower, however, because it fails to account for any of the other factors that might have influenced alcohol consumption.

The remaining columns of the table take a first step toward controlling for these others factors, specifically, for the lag structure in the consumption and cirrhosis processes implied by consumption theory. Allowing simply for lags in the effect of alcohol consumption on cirrhosis (column (2)) barely changes the estimated impact of Prohibition, although the implied standard error on this impact increases. The OLS estimates that allow for myopic or rational addiction (columns (3)-(4)) suggest a much smaller impact of Prohibition, and in neither case is the estimated impact significant. The IV

\footnotetext{
${ }^{5}$ In column (5) the instruments are the second and third lags of cirrhosis while in column (6) they are the third, fourth, and fifth lags of cirrhosis.
} 
estimate that allows for addictiveness but assumes myopia implies a small positive effect of Prohibition, while the IV estimate that allows for rationality is unstable. These baseline results suggest that Prohibition reduced alcohol consumption by at most a moderate amount; according to the results in column (4), for example, Prohibition reduced the cirrhosis death rate by about 21 percent compared to its average non-Prohibition value.

The analysis presented so far does not account for a number of factors that might have mediated the relation between Prohibition and cirrhosis. I now investigate whether accounting for those factors modifies the conclusions of the analysis above.

\subsection{Cirrhosis and the Age Structure of the Population}

One potentially important omission from the specification examined so far is the age structure of the population. At a minimum, Table 1 documents that the age structure has an important impact on the cirrhosis death rate and should therefore be included in the estimation of equation (15). In addition, age is known to be a critical determinant of alcohol consumption (e.g., Blane and Chafetz (1979)), which suggests the age structure should be included in the estimation even if it has no direct effect on cirrhosis.

I address this issue by introducing as regressors the same age structure variables considered in Table 1, namely, the fraction of the population in the age groups 5 -14, 15-24, .. , 45-64, and 65 and over. I also include the first or first and second lags of these variables, as relevant. Inclusion of the lags follows both from the derivation of (7) under the assumption that the marginal utility of alcohol consumption is additively age dependent and from the substitution of (14) into (7). Under this approach, the coefficients on the age variables are potentially hard to interpret, since they capture two logically distinct mechanisms, but the set of such variables should capture most of the relevant age effects.

Table 3 repeats the regressions shown in Table 2, but with the age structure variables included as controls. The introduction of these variables has a dramatic effect on the implied impact of Prohibition. In the naive case that ignores all lags (column (1)), Prohibition is still statistically significant but this estimated impact falls by more than half compared to Table 2. Under the assumption of non-addictiveness, in column (2), the estimated impact is still negative but statistically insignificant and tiny. In the specifications that allow preferences to be addictive and rational, the estimated impact of Prohibition is small or even positive although never statistically signif- 
icant. Comparing Table 3 with Table 2 indicates that controlling for the age structure of the population generally implies a less negative impact of Prohibition.

One interesting difference between the results in Tables 2 and 3 is that the estimated persistence of cirrhosis is lower, for any given specification, once the age structure of the population is included. This is consistent with the results in Table 1, in which introduction of the age variables also reduces the estimated persistence of cirrhosis. Thus, one reason the cirrhosis death rate appears highly persistent is because the condition that allows it to operate - a pool of persons the appropriate age - is itself highly persistent. Once this has been accounted for, cirrhosis is less persistent, so the implied impact of any given coefficient estimate on the Prohibition dummies is lower.

The positive impact of Prohibition reported in columns (3) and (4) of Table 3 is puzzling, since the standard assumption is that Prohibition raised the costs of producing and supplying alcohol, thereby implying higher prices for any given demand curve. Even if demand is totally price inelastic, higher prices should not increase consumption. I defer discussion of this issue for now, since the introduction of other relevant factors into the analysis might imply significant changes in this result. It turns out, however, that the result is fairly general, so I discuss it in detail in Section 5 .

\subsection{World War I}

The next issue to address is the role of World War I, which might have affected the path of cirrhosis and alcohol consumption via a number of possible mechanisms. To begin with, Congress restricted the use of food in the manufacture of alcoholic beverages begining in September, 1917, and it outlawed the sale of alcoholic beverages beginning in July, 1919 (Schmeckebier, 1929, pp.4-5). Second, patriotism might have discouraged consumption of alcohol, since grain and other raw ingredients were considered vital to the war effort. Third, the incredible casualty rate due to WWI, the world-wide flu epidemic during World War I, and the pre-war decline in immigration might have altered the demographic structure of the population in ways not fully captured by the age structure variables considered above. Finally, antiGerman sentiment might have affected preferences for alcohol, although this could have shown up merely as a switch from beer to spirits or wine.

To account for these effects, Table 4 reports estimates that include a dummy variable for the years 1917 through 1919. The results show first of all that cirrhosis fell substantially in the years just prior to the onset 
of constitutional prohibition, as Figure 1 suggests. In the most general specification, for example, the estimated impact is approximately 25 percent of the non-Prohibition value of cirrhosis. The results also show, however, that inclusion of this dummy has little effect on the estimated impact of Prohibition. The estimated impact is now negative under both OLS and IV, but the magnitude is small (less than $15 \%$ of the non-Prohibition value in the specifications that allow for addictiveness) and statistically insignificant. These results are not sensitive to the exact specification of the "WWI" dummy; similar results hold with a dummy for 1917-1918, 1918, or 19181919.

At a purely statistical level, the interpretation of the results in Table 4 is straightforward. Beginning around 1917-1918, some factor or set of factors reduced cirrhosis substantially relative to its usual level. Given the low level cirrhosis obtained just before Prohibition, its subsequent evolution was then almost exactly what was implied by the natural dynamics of cirrhosis, alcohol consumption, and the age structure of the population. In particular, constitutional prohibition played virtually no role in reducing cirrhosis below what it would have been otherwise.

At an economic level, the interpretation of these results is less obvious, since a number of policy and non-policy events all occurred during the two to three years just before Prohibition. On the policy side, the war-time restrictions on the use of food products to make alcoholic beverages seem unlikely to have created such dramatic reductions in cirrhosis or alcohol consumption, since these restrictions did not prevent consumption of imports or existing stocks, and the budget for enforcement of these restrictions was essentially zero. Moreover, reductions in alcohol consumption are unlikely to have caused such large contemporaneous declines in cirrhosis. War-time prohibition per se could not possibly have caused the initial drops in consumption or cirrhosis since it did not take effect until July 1, 1919.

A more plausible explanation for these dramatic changes in consumption and cirrhosis is fluctuations in the age structure of the population that are not accounted for by the age variables included in the regressions. Until 1920, annual estimates of the age composition of the population were based on interpolations of decadal census data without information from annual data on births, deaths or immigration (Bureau of the Census, 1965). Thus, for the pre-1920 period, the age composition variables might miss important influences on cirrhosis and consumption.

This hypothesis is particularly appealing because there are two likely sources of major changes in the relevant aspects of the age structure. First, 
immigration into the United States fell dramatically beginning in 1915, from more than 1 million per year in 1913-1914 to fewer than three hundred thousand per year in 1917-1919. Not only were many immigrants of this period from cultures that tended to consume alcohol heavily; many immigrants were also young and male, which tends to correlate with high alcohol consumption and cirrhosis. Second, World War I and the flu epidemic of 1918 produced an enormous surge in the death rate, and this increase was highest amongst males, including those in the age ranges susceptible to cirrhosis (Bureau of the Census, 1975, pp.58-62). The population at risk of cirrhosis was therefore likely to have been substantially reduced during the years 1917-1919 relative to other periods.

Thus, it is possible if not likely that much of the dramatic pre-1920 fall in cirrhosis and consumption reflected demographics, just as did most of the fluctuations after 1920. Without accurate data on the age composition, this proposition cannot be proved definitively. But there is little evidence that policies directed toward alcohol played a substantial role in causing the 1917-1919 reductions in cirrhosis or alcohol consumption. And even if one attributes the 1917-1919 declines to policy factors, the failure of constitutional prohibition to affect cirrhosis means that any effects of the pre-1920 policies were temporary rather than permanent.

\subsection{Additional Issues}

In addition to the factors considered so far, there are a number of other issues that need to be addressed in a complete assessment of Prohibition's impact on cirrhosis and alcohol consumption. For example, all the specifications above assume Prohibition can be modeled simply as a dummy variable for the period of constitutional prohibition. This specification assumes that Prohibition's impact was constant throughout its existence, but since it takes time for an illegal supply network to develop, the short-term and longterm impacts might well have been different. Similarly, the dummy variable approach to measuring Prohibition's impact might be inaccurate if that impact depends on the level of resources devoted to enforcement, not merely on the existence of Prohibition. Moreover, state-level prohibitions were in operation during parts of the period outside constitutional prohibition, and drug prohibition took effect beginning in 1914. Finally, real tax rates on alcoholic beverages have varied substantially over time.

Each of these factors can be addressed by substituting or adding appropriate variables to the specification in Table 4. To account for the possibil- 
ity that Prohibition's short-run impact differed from its long-run impact, I break the Prohibition dummy into an early prohibition dummy (1920-1926) and a late prohibition dummy (1927-1933). To account for the possibility that Prohibition's impact varied with the level of enforcement, I include a measure of expenditures on enforcement of Prohibition. To account for the possibility that state-level prohibitions played a role in reducing alcohol consumption, I include a measure of the number of states with state-level prohibition. To account for drug prohibition, I include dummy variables for periods when particular drugs were prohibited. To account for the effects of alcoholic beverage taxes, I include a measure of the tax rate on alcohol.

The measure of enforcement employed is the per capita real dollars of expenditure by those Federal agencies devoted expressly to enforcement of the Prohibition laws (U.S. Treasury (1932) and Statistical Abstracts of the United States). The measure therefore excludes expenditures by agencies that existed mainly for other purposes but that might have been significantly involved in enforcing Prohibition. ${ }^{6}$ I adopt this approach mainly because it is difficult to apportion the expenditure of the "non-Prohibition" agencies between Prohibition-enforcement and other activities. As long as those expenditures increased approximately in line with more direct expenditures, this omission should not be a problem. A different issue is that the measure used here omits expenditures by state or local governments, which could bias the results if these were substantial and not well correlated with Federal efforts. Warburton (1932, p.247) indicates, however, that state-level expenditures were small (only about seven hundred thousand dollars per year compared to an average of more than 10 million at the federal level) and that states did not appear to be spending any more for enforcment of constitutional prohibition than they had previously spent on enforcement of their own state prohibitions. Thus, the omission of state expenditures from the measure of enforcement is probably not critical.

The measure of state prohibitions is the number of states with statewide prohibitions on alcohol during the 1900-1919 period (Wickersham, v.5, (1931), pp.640-641). This specification assumes that all states had de facto or de jure state-level prohibition during constitutional prohibition, and it ignores the fact that a few states failed to repeal their state-level prohibitions immediately after the repeal of constitutional prohibition. States did

\footnotetext{
${ }^{6}$ In particular, this measure excludes substantial sums appropriated to the Coast Guard for enforcement of Prohibition (Warburton (1932), p.246). Data limitations make it problematic to include these expenditures, but estimates of Prohibition's impact based on the best available data are similar to those reported in Table 5.
} 
differ in their enthusiasm for Prohibition even during constitutional prohibition, but since Federal expenditure was so much greater than total state expenditure, the variations across states during constitutional prohibition are unlikely to have played a significant role. Similarly, it is unlikely that the small number of states that continued their prohibitions after the end of constitutional prohibition could have substantially influenced overall alcohol consumption (see, e.g., Holder and Cherpitel (1996) on Mississippi).

The measure of drug prohibition is a dummy variable equal to one beginning in 1914, when opiates and cocaine were de facto prohibited by the Harrison Act, and equal to two beginning in 1937, when marijuana was prohibited by the Marijuana Tax Act. State-level laws also prohibited some or all of these drugs at various points during the relevant sample, but these laws were sporadic, poorly enforced, and easily susceptible to cross-border smuggling. Regressions with separate dummies for the Harrison and Marijuana Acts yield results similar to those reported here. Measuring the total enforcement budget for drug prohibition is beyond the scope of this paper.

The tax rate on alcohol is measured as the real implicit tax rate on all alcoholic beverages. For the non-Prohibition period, this measure is constructed by dividing total collections of alcoholic beverage taxes (both federal and state/local) by total gallons of pure alcohol consumed and then deflating. ${ }^{7}$ For the Prohibition period, the measure is set equal to zero, under the assumption that most alcohol transactions did not pay taxes during this period. I also consider two alternative measures of the tax rate on alcohol, the real federal statutory tax rates on spirits and beer, respectively (Hu (1950) and Facts and Figures on Government Finance, various issues). These measures do not account for the effects of state (or local) alcohol taxes, so they might be biased to the extent that federal tax rates behaved differently from state rates. As it turns out, however, the second and third measures are highly positively correlated with the implicit tax rate, so the bias due to this omission is probably small. ${ }^{8}$

Table 5 summarizes the results from adding or substituting various combinations of these variables in the specification reported in Table 4. For parsimony, I report only the estimated impact of constitutional prohibition and of the additional variables, and I consider only the most general speci-

\footnotetext{
${ }^{7}$ The data on collections of alcoholic beverage taxes are from Bureau of the Census (1975), Annual Reports of the Commissioner of the Internal Revenue Service, various issues, and Facts and Figures on Government Finance, various issues.

${ }^{8}$ The correlation between the implicit tax rate and the spirits tax is 0.96 , while that between the implicit tax rate and the beer tax is 0.57 .
} 
fication that allows for a full set of lags. Each specification includes the age structure variables and the dummy variable for the 1917-1919 period.

The bottom line is that none of these modifications changes the conclusion stated so far: constitutional prohibition had a small, statistically insignificant, and possibly even a positive impact on the cirrhosis death rate. Several specific features of these results are worth discussing in detail, however.

The estimate of late Prohibition's impact is similar to that found for overall Prohibition in Table 4. According to the OLS estimates, the estimated impact of late Prohibition differs substantially from that of early Prohibition, which is estimated to be positive. This pattern of results might suggest that any glamorization effect of Prohibition diminished over time or that enforcement became more effective as its level increased. Both estimated impacts have large standard errors, however, so it is probably a mistake to draw strong conclusions. According to the IV estimates, late Prohibition had a slightly smaller effect than early Prohibition, consistent with the hypothesis that the black market became better developed over time.

The results that employ enforcement of Prohibition rather than the Prohibition dummy suggest that this enforcement, evaluated at the maximum value attained by enforcement in the sample, had a small, negative impact on cirrhosis. The OLS results that include both the Prohibition dummy and expenditure find a slightly more negative impact of enforcement but a partially offsetting positive impact of the Prohibition dummy. The IV results that include both enforcement and the Prohibition dummy finds the opposite sign pattern - positive on enforcement, negative on the dummy - but overall a similar net effect. Conducting the analysis with alternative measures of the enforcement variable - expenditure per dollar of GDP rather than expenditure per capita - yields very similar results.

The impact of drug prohibition is estimated to be negative, which is inconsistent with the view that drugs and alcohol are substitutes. Similarly, the tax rate variable always enters positively, contrary to theory. The drug dummy is an extremely crude measure of drug prohibition, and small sample effects might be at work with respect to both variables. Further, both the level of the alcohol tax rate and the existence of drug prohibition might be endogenous with respect to alcohol consumption. Still, these results are puzzling and require scrutiny in further work. The introduction of these variables does not alter the conclusion, however, that constitutional prohibition failed to reduce alcohol consumption substantially; indeed, every 
specification that contains the alcohol tax rate implies a large positive effect of Prohibition-cum-enforcement.

\subsection{Was Prohibition Exogenous?}

The results presented above make a strong case that Prohibition failed to reduce the consumption of alcohol and might even have raised it slightly. That conclusion relies, naturally, on the assumption that Prohibition itself can be treated as exogenous. If the initiation or repeal of Prohibition, or the level of enforcement during Prohibition, was partially a response to changes in alcohol consumption, then the estimates reported above are biased. For example, if Prohibition was enacted because of increasing consumption and repealed due to declining consumption, the estimates reported here understate the true effect of Prohibition on alcohol consumption.

It is not possible to rule out this kind of bias on a priori grounds: the exogeniety of Prohibition is the key identifying assumption of this paper. Nevertheless, a number of related kinds of evidence at least make plausible that the existence and enforcement of Prohibition were not substantially affected by the behavior of alcohol consumption.

To begin, consumption was decreasing shortly before Prohibition took effect and increasing for several years after it was repealed; this does not prove what alcohol consumption would have been during the Prohibition years in the absence of Prohibition, but it suggests just the opposite correlation between Prohibition and alcohol consumption from that which would cause the estimates reported here to understate Prohibition's true impact on alcohol consumption.

In addition, historical accounts cite a broad range of factors other than alcohol consumption as causing both Prohibition and its repeal. One factor leading to Prohibition was the huge number of immigrants during the first decade and a half of the 20th century, since popular wisdom held that immigrants were heavy drinkers. A second factor was increasing urbanization, which made the presence of the hard drinking, saloon frequenting, urban poor more visible. (Clark, 1976). U.S. involvement in World War I may also have played a significant role, by legitimating the view that turning grain into alcohol was wasteful (Merz, 1932), by creating an air of moral certainty that facilitated passage of prohibition (Sinclair, 1962), and by producing a distaste for anything German (i.e., beer). The two key factors usually credited with precipitating Prohibition's demise (Levine and Reinarman, 1991) are the Great Depression, which both invalidated dry claims 
that Prohibition promoted prosperity and produced a need for tax revenue, and the increasing violence associated with Prohibition (Friedman, 1991). None of these analyses can rule out changes in alcohol consumption as one factor contributing to the initiation or elimination of Prohibition, but the existence of other important factors does suggest bounds on the magnitude of any endogeneity.

The other crucial fact to note in this context is that the age structure of the population explains an enormous fraction of the variation in alcohol consumption outside of the Prohibition period and of the variation in cirrhosis over both the entire period and the non-Prohibition period. A regression of either alcohol consumption or cirrhosis on a constant and the seven age structure variables used above always yields an $R^{2}$ in excess of 0.87 , and for the 1934-1994 period (which excludes the interpolated age structure observations) the $R^{2}$ is 0.98 for alcohol and 0.95 for cirrhosis. Thus, there is just not that much variation in consumption or cirrhosis left for Prohibition to explain, even if the estimates reported here are biased. Of course, Prohibition might have changed the relation between the age structure and consumption or cirrhosis, but the magnitude of that change would have had to have been substantial for the basic message here to be seriously in error.

\section{Discussion}

The analysis above suggests that Prohibition exerted a minimal effect on the per capita consumption of alcohol. Indeed, many specifications, including some of those most defensible on a priori grounds, show positive effects of Prohibition on cirrhosis and, by implication, alcohol consumption. Even the most extreme of the estimates that allows for addiction and rationality implies that Prohibition caused less than a 15 percent decline in cirrhosis relative to its non-Prohibition value. These are surprising results that require discussion from several perspectives.

One critical issue is the relation between these results and existing work on the elasticity of the demand for alcohol. That literature offers a broad range of estimates, from virtually zero for certain subgroups to well in excess of -1.0 overall. ${ }^{9}$ Even taking the lowest estimates, however, a puzzle remains

\footnotetext{
${ }^{9}$ See Phelps and Leung (1991) for a detailed review, and Chaloupka, Grossman, Becker and Murphy (1993), Chaloupka and Grossman (1994), Manning, Blumberg, and Moulton (1995), Grossman, Chaloupka, and Sirtalan (1995), Chaloupka and Wechsler (1995) and Moore and Cook (1995) for more recent work.
} 
because some of the regressions that are most plausible a priori suggest a positive effect of Prohibition on consumption. This does not follow from any standard preference structure even with totally inelastic demand.

An alternative explanation for the modest effect of Prohibition on consumption is that Prohibition created a forbidden fruit effect, thereby increasing preferences for alcohol and partially or perhaps fully offsetting the depressing effects on demand of higher prices. This hypothesis receives anecdotal support in some contexts, and accounts of drinking behavior during Prohibition are consistent with such an effect (e.g., the term "roaring 20s"). Without a specific model of the forbidden fruit effect, however, (does it depend on the mere existence of a prohibition, or on the level of enforcement as well? does it affect some groups more than others, and why? etc), one cannot interpret the evidence here as strong evidence for such an effect. Nevertheless, the inability of other hypotheses to fully account for the empirical results at least makes this hypothesis interesting.

A final issue is whether Prohibition in fact raised the price of alcohol. Enforcement of prohibition and perhaps the mere existence of prohibition tends to raise some costs of supplying a prohibited commodity, and rough calculations suggest that the level of expenditure on Alcohol Prohibition was comparable to recent levels of expenditure on drug prohibition; thus, the standard presumption is that Prohibition raised alcohol prices substantially. Under prohibition, however, suppliers face low marginal costs of evading various kinds of costly government regulation, including income taxes, excise taxes, child labor laws, environmental regulation, union labor laws, and occupational health and safety regulation, amongst others. Many of these kinds of government regulation were absent during the Prohibition era, but several were present and substantial. Further, prohibition can help maintain a market equilibrium in which suppliers do not advertise, which then permits prices to fall relative to a legal market (Motta 1997). Thus, it is possible that Prohibition failed to raise alcohol prices and might even have lowered them.

The key question, then, is what happened to alcohol prices during Prohibition. The conventional wisdom (e.g., Thornton (1991)) is based on data in Warburton (1932) and Fisher (1926, 1928), and it holds that prices increased substantially between the pre-Prohibition and Prohibition periods, perhaps by as much as several hundred percent on average. Re-examination of this evidence, however, suggests a more nuanced picture.

The first problem with the standard view is that it neglects the behavior of the overall price level. Warburton's data compare prices between 1911- 
1915 and 1926-1930, while Fisher's compare prices between 1916 and 1928. Both authors examine the behavior of nominal prices, yet the price level increased by approximately 75 per cent between these two periods (Bureau of the Census (1975), p.211). Thus, at a minimum, the raw data presented by Warburton and Fisher overstate the increase in the relative price of alcohol.

In addition, Warburton presents a broad range of prices for the Prohibition period, and the lowest prices reported suggest that, even ignoring inflation, some alcoholic beverage prices fell relative to the pre-Prohibition period. This does not prove that consumers paid less, on average, for alcohol, but they certainly faced an incentive to buy at the lowest prices and then stockpile the quantities purchased at these prices. The available data do not allow computation of the average price actually paid, and the extremely high prices reported in many cases by both Warburton and Fisher allow for the possibility that the average price paid in fact rose. But the magnitude of this rise is undoubtedly less than they asserted, and it is at least possible prices failed to rise substantially overall. If prices did not increase very much, there is no puzzle in the failure of consumption to fall substantially.

Determining which of the above hypotheses is the best interpretation of the factual results in this paper is not possible without further research. The implications of any interpretation, however, are important for policy towards a wide variety of currently prohibited activities. 


\section{References}

[1] Becker, Gary S. and Kevin M. Murphy (1988), "A Theory of Rational Addiction," Journal of Political Economy, 96, 675-700.

[2] Becker, Gary S., Michael Grossman, and Kevin M. Murphy. "An Empirical Analysis of Cigarette Addiction." American Economic Review, 84, June 1994, 396-418.

[3] Berkow, Robert, ed., The Merck Manual. 16th ed. Rahway, N.J.: Merck and Co., Inc., 1992.

[4] Blane, Howard T. and Morris E. Chafetz, eds., Youth, Alcohol and Social Policy, New York: Plenum Press, 1979.

[5] Blocker, Jack S. (1994), "Consumption and Availability of Alcoholic Beverages in the United States, 1863-1920," Contemporary Drug Problems, 21(4), Winter, 631-666.

[6] Bureau of the Census (1965), Current Population Reports: Population Estimates, Series P-25, No. 311, Washington: USGPO.

[7] Bureau of the Census (1975), Historical Statistics of the United States, Washington: USGPO.

[8] Chaloupka, Frank J. (1991), "Rational Addictive Behavior and Cigarette Smoking," Journal of Political Economy, 99, 4(August), 722-742.

[9] Chaloupka, Frank J., Michael Grossman, Gary S. Becker, and Kevin M. Murphy (1993), "Alcohol Addiction: An Econometric Analysis," manuscript, University of Illinois at Chicago.

[10] Chaloupka, Frank J. and Michael Grossman (1994), "Drinking and Addiction? Evidence from the First National Health and Nutritution Examination Survey," manuscript, University of Illinois at Chicago.

[11] Chaloupka, Frank J. and Henry Wechsler (1995), "The Impact of Price, Availability, and Alcohol Control Policies on Binge Drinking in College," NBER WP \#5319.

[12] Clark, Norman H. (1976), Deliver Us From Evil: An Interpretation of American Prohibition, W.W. Norton and Compancy: New York. 
[13] Cook, P.J. (1981), "The Effect of Liquor Taxes on Drinking, Cirrhosis, and Auto Accidents," in M.H. Moore and D.R. Gerstein, eds., Alcohol and Public Policy: Beyond the Shadow of Prohibition, National Academy Press, Washington, 255-85.

[14] Cook, P.J. and Tauchen, G., "The Effect of Liquor Taxes on Heavy Drinking," Bell Journal of Economics, 1982, 13, 379-390.

[15] Fisher, Irving (1928), Prohibition Still at Its Worst, New York: Alcohol Information Committee.

[16] Fisher, Irving (1930), The Noble Experiment, New York: Alcohol Information Committee.

[17] Friedman, Milton (1991), "The War We Are Losing," in Krauss, Meyvyn B. and Edward P. Lazear, eds., Searching for Alternatives: DrugControl Policy in the United States, Stanford, CA: Hoover Institution, pp.53-67.

[18] Grossman, Michael, Frank J. Chaloupka, and Ismail Sirtalan (1995), "An Empirical Analysis of Alcohol Addiction: Results from the Monitoring the Future Panels," NBER WP \#5200.

[19] Holder, Harold D. and Cheryl J. Cherpitel (1996), "The End of U.S. Prohibition: A Case Study of Mississippi," Contemporary Drug Problems, 23(2), Summer, 301-330.

[20] Hu, Tun Yuan (1950), The Liquor Tax in the United States, 1791-1947: A History of the Internal Revenue Taxes Imposed on Distilled Spirits by the Federal Government, Graduate School of Business, Columbia University: New York.

[21] Levine, Harry G. and Craig Reinarman (1991), "From Prohibition to Regulation: Lessons from Alcohol Policy for Drug Policy," The Milbank Quarterly, 69, 1-43.

[22] Manning, Willard G., Linda Blumberg, and Lawrence H. Moulton (1995), "The Demands for Alcohol: The Differential Response to Price," Journal of Health Economics, 14, 2(June), 123-48.

[23] Merz, Charles (1932), The Dry Decade, Garden City, NY: Doubleday, Doran and Co. 
[24] Miron, Jeffrey A. (1996), "Some Estimates of Annual Alcohol Consumption Per Capita, 1870-1991," ISP Discussion Paper \#69, Department of Economics, Boston University.

[25] Miron, Jeffrey A. and Jeffrey Zwiebel (1991), "Alcohol Consumption During Prohibition," American Economic Review, 81(2), May, 242-247.

[26] Miron, Jeffrey A. and Jeffrey Zwiebel (1995), "The Economic Case Against Drug Prohibition," Journal of Economic Perspectives, 9(4), Fall, 175-192.

[27] Moore, Michael J. and Philip J. Cook (1995), "Habit and Heterogeneity in the Youthful Demand for Alcohol," NBER WP \#5152.

[28] Motta, Massimo (1997), "Advertising Bans," manuscript, Department of Economics, University of Pompeu Fabra, Barcelona, Spain.

[29] Newey, Whitney and Kenneth West, "A Simple, Positive Definite, Heteroskedasticity and Autocorrelation Consistent Covariance Matrix," Econometrica, 1987, 55, 703-8.

[30] Phelps, Charles E. and Sui-Fai Leung (1991), "My Kingdom for a Drink? A Review of Estimates of the Price Sensitivity of Demand for Alcoholic Beverages," manuscript, University of Rochester.

[31] Schmeckebier, Laurence F. (1929), The Bureau of Prohibition: Its History, Activites, and Organization, The Brookings Institution: Washington.

[32] Sinclair, Andrew (1962), Prohibition: The Era of Excess, Faber and Faber: London.

[33] Thornton, Mark (1991), The Economics of Prohibition, University of Utah Press: Salt Lake City.

[34] U.S. Department of Treasury (1932), Statistics Concerning Intoxicating Liquors, Washington: USGPO.

[35] Warburton, Clark (1932), The Economic Results of Prohibition, Columbia University Press: New York.

[36] Wickersham, George W. (1931), Enforcement of the Prohibition Laws, v.5, U.S. Government Printing Office: Washington. 
Table 1

Regressions of Cirrhosis on Alcohol Consumption

\begin{tabular}{|c|c|c|c|c|c|c|}
\hline \multirow[b]{2}{*}{ Constant } & \multicolumn{3}{|c|}{ Age Variables Excluded } & \multicolumn{3}{|c|}{ Age Variables Included } \\
\hline & $\begin{array}{c}5.84 \\
(4.87)\end{array}$ & $\begin{array}{c}0.36 \\
(0.75)\end{array}$ & $\begin{array}{c}0.34 \\
(0.72)\end{array}$ & $\begin{array}{l}41.28 \\
(1.57)\end{array}$ & $\begin{array}{c}3.03 \\
(0.13)\end{array}$ & $\begin{array}{r}-10.23 \\
(0.49)\end{array}$ \\
\hline Trend & $\begin{array}{l}-0.03 \\
(3.27)\end{array}$ & $\begin{array}{c}0.00 \\
(0.00)\end{array}$ & $\begin{array}{c}0.00 \\
(0.58)\end{array}$ & $\begin{array}{l}-0.03 \\
(0.54)\end{array}$ & $\begin{array}{l}-0.10 \\
(2.16)\end{array}$ & $\begin{array}{l}-0.10 \\
(2.04)\end{array}$ \\
\hline Alcohol & $\begin{array}{c}5.17 \\
(7.39)\end{array}$ & & $\begin{array}{l}-0.33 \\
(0.78)\end{array}$ & $\begin{array}{c}3.51 \\
(3.83)\end{array}$ & & $\begin{array}{c}1.54 \\
(2.12)\end{array}$ \\
\hline Lagged Cirrhosis & & $\begin{array}{c}0.97 \\
(33.11)\end{array}$ & $\begin{array}{c}1.00 \\
(18.92)\end{array}$ & & $\begin{array}{c}0.86 \\
(5.21)\end{array}$ & $\begin{array}{c}0.70 \\
(4.27)\end{array}$ \\
\hline Impact of Alcohol & $\begin{array}{c}5.17 \\
(.000)\end{array}$ & & $\begin{array}{l}-75.2 \\
(.994)\end{array}$ & $\begin{array}{c}3.51 \\
(.000)\end{array}$ & & $\begin{array}{c}5.06 \\
(.000)\end{array}$ \\
\hline Age Effects & & & & $(.000)$ & $(.000)$ & $(.000)$ \\
\hline $\mathrm{N}$ & 80 & 79 & 79 & 80 & 79 & 79 \\
\hline$R^{2}$ & .50 & .93 & .94 & .94 & .96 & .96 \\
\hline
\end{tabular}

Newey and West (1987) t-statistics in parentheses. 
Table 2

Regressions of Cirrhosis on Prohibition Dummy

\begin{tabular}{|c|c|c|c|c|c|c|}
\hline & OLS & OLS & OLS & OLS & IV & IV \\
\hline Cirrhosis $_{t-1}$ & & $\begin{array}{c}0.96 \\
(33.4)\end{array}$ & $\begin{array}{c}1.21 \\
(6.63)\end{array}$ & $\begin{array}{c}1.20 \\
(7.32)\end{array}$ & $\begin{array}{c}1.50 \\
(3.16)\end{array}$ & $\begin{array}{c}1.70 \\
(1.91)\end{array}$ \\
\hline Cirrhosis $_{t-2}$ & & & $\begin{array}{l}-0.25 \\
(1.45)\end{array}$ & $\begin{array}{l}-0.16 \\
(1.29)\end{array}$ & $\begin{array}{l}-0.53 \\
(1.16)\end{array}$ & $\begin{array}{c}0.24 \\
(0.18)\end{array}$ \\
\hline Cirrhosis $_{t-3}$ & & & & $\begin{array}{l}-0.08 \\
(0.69)\end{array}$ & & $\begin{array}{l}-0.92 \\
(1.23)\end{array}$ \\
\hline Prohibition & $\begin{array}{l}-4.37 \\
(7.47)\end{array}$ & $\begin{array}{l}-0.16 \\
(0.96)\end{array}$ & $\begin{array}{l}-0.34 \\
(1.52)\end{array}$ & $\begin{array}{l}-0.31 \\
(1.21)\end{array}$ & $\begin{array}{l}-0.03 \\
(0.07)\end{array}$ & $\begin{array}{r}0.78 \\
(0.70)\end{array}$ \\
\hline Prohibition $_{t-1}$ & & & $\begin{array}{c}0.26 \\
(1.82)\end{array}$ & $\begin{array}{c}0.46 \\
(2.08)\end{array}$ & $\begin{array}{r}0.04 \\
(0.11)\end{array}$ & $\begin{array}{c}0.66 \\
(0.92)\end{array}$ \\
\hline Prohibition $_{t-2}$ & & & & $\begin{array}{l}-0.26 \\
(1.00)\end{array}$ & & $\begin{array}{l}-1.08 \\
(1.14)\end{array}$ \\
\hline Impact of Prohibition & $\begin{array}{l}-4.37 \\
(.000)\end{array}$ & $\begin{array}{l}-4.42 \\
(.000)\end{array}$ & $\begin{array}{l}-1.95 \\
(.604)\end{array}$ & $\begin{array}{l}-2.45 \\
(.459)\end{array}$ & $\begin{array}{c}0.17 \\
(.982)\end{array}$ & $\mathrm{NC}$ \\
\hline $\mathrm{N}$ & 94 & 93 & 92 & 91 & 91 & 89 \\
\hline$R^{2}$ & .38 & .96 & .96 & .96 & .96 & .91 \\
\hline
\end{tabular}

Newey and West (1987) t-statistics in parentheses.

$\mathrm{NC}=$ not computed because estimated roots of equation are unstable. 
Table 3

Regressions of Cirrhosis on Prohibition Dummy, Age Variables Included

\begin{tabular}{|c|c|c|c|c|c|c|}
\hline & OLS & OLS & OLS & OLS & IV & IV \\
\hline Cirrhosis $_{t-1}$ & & $\begin{array}{c}0.80 \\
(7.49)\end{array}$ & $\begin{array}{c}0.68 \\
(4.07)\end{array}$ & $\begin{array}{c}0.64 \\
(3.65)\end{array}$ & $\begin{array}{l}-0.19 \\
(0.17)\end{array}$ & $\begin{array}{l}-1.21 \\
(0.54)\end{array}$ \\
\hline Cirrhosis $_{t-2}$ & & & $\begin{array}{l}-0.01 \\
(0.10)\end{array}$ & $\begin{array}{c}-0.17 \\
(1.31)\end{array}$ & $\begin{array}{r}0.49 \\
(0.78)\end{array}$ & $\begin{array}{r}0.42 \\
(0.25)\end{array}$ \\
\hline Cirrhosis $_{t-3}$ & & & & $\begin{array}{c}0.24 \\
(1.72)\end{array}$ & & $\begin{array}{r}0.29 \\
(0.29)\end{array}$ \\
\hline Prohibition & $\begin{array}{l}-2.02 \\
(3.74)\end{array}$ & $\begin{array}{l}-0.00 \\
(0.00)\end{array}$ & $\begin{array}{l}-0.26 \\
(0.78)\end{array}$ & $\begin{array}{c}-0.34 \\
(1.03)\end{array}$ & $\begin{array}{l}-0.99 \\
(0.85)\end{array}$ & $\begin{array}{l}-1.95 \\
(0.83)\end{array}$ \\
\hline Prohibition $_{t-1}$ & & & $\begin{array}{c}0.32 \\
(1.82)\end{array}$ & $\begin{array}{c}0.44 \\
(1.18)\end{array}$ & $\begin{array}{r}0.74 \\
(1.16)\end{array}$ & $\begin{array}{r}0.46 \\
(0.26)\end{array}$ \\
\hline Prohibition $_{t-2}$ & & & & $\begin{array}{c}0.16 \\
(0.66)\end{array}$ & & $\begin{array}{r}0.88 \\
(0.58)\end{array}$ \\
\hline Impact of Prohibition & $\begin{array}{l}-2.02 \\
(.000)\end{array}$ & $\begin{array}{l}-0.01 \\
(.997)\end{array}$ & $\begin{array}{c}0.17 \\
(.898)\end{array}$ & $\begin{array}{c}0.84 \\
(.550)\end{array}$ & $\begin{array}{l}-0.36 \\
(.703)\end{array}$ & $\begin{array}{l}-0.40 \\
(.610)\end{array}$ \\
\hline $\mathrm{N}$ & 94 & 93 & 92 & 91 & 91 & 89 \\
\hline$R^{2}$ & .93 & .97 & .98 & .98 & .96 & .92 \\
\hline
\end{tabular}

Newey and West (1987) t-statistics in parentheses. 
Table 4

Regressions of Cirrhosis on Prohibition Dummy and WWI Dummy, Age Variables Included

\begin{tabular}{|c|c|c|c|c|c|c|}
\hline & OLS & OLS & OLS & OLS & IV & IV \\
\hline Cirrhosis $_{t-1}$ & & $\begin{array}{c}0.78 \\
(7.78)\end{array}$ & $\begin{array}{c}0.55 \\
(4.27)\end{array}$ & $\begin{array}{c}0.47 \\
(3.54)\end{array}$ & $\begin{array}{l}-0.93 \\
(0.49)\end{array}$ & $\begin{array}{l}-1.09 \\
(0.54)\end{array}$ \\
\hline Cirrhosis $_{t-2}$ & & & $\begin{array}{c}0.10 \\
(1.03)\end{array}$ & $\begin{array}{l}-0.10 \\
(0.80)\end{array}$ & $\begin{array}{c}1.02 \\
(0.91)\end{array}$ & $\begin{array}{r}0.06 \\
(0.02)\end{array}$ \\
\hline Cirrhosis $_{t-3}$ & & & & $\begin{array}{c}0.29 \\
(2.08)\end{array}$ & & $\begin{array}{c}0.63 \\
(0.45)\end{array}$ \\
\hline Prohibition & $\begin{array}{l}-2.57 \\
(4.45)\end{array}$ & $\begin{array}{c}-0.51 \\
(1.92)\end{array}$ & $\begin{array}{l}-0.34 \\
(1.81)\end{array}$ & $\begin{array}{l}-0.15 \\
(0.66)\end{array}$ & $\begin{array}{l}-1.09 \\
(0.98)\end{array}$ & $\begin{array}{l}-0.62 \\
(0.84)\end{array}$ \\
\hline Prohibition $_{t-1}$ & & & $\begin{array}{c}-0.04 \\
(0.23)\end{array}$ & $\begin{array}{c}0.06 \\
(0.40)\end{array}$ & $\begin{array}{c}-0.04 \\
(0.09)\end{array}$ & $\begin{array}{l}-0.54 \\
(0.31)\end{array}$ \\
\hline Prohibition $_{t-2}$ & & & & $\begin{array}{l}-0.08 \\
(0.34)\end{array}$ & & $\begin{array}{c}-0.00 \\
(0.01)\end{array}$ \\
\hline War-Prohibition & $\begin{array}{l}-1.56 \\
(3.15)\end{array}$ & $\begin{array}{l}-1.23 \\
(5.16)\end{array}$ & $\begin{array}{l}-0.52 \\
(3.86)\end{array}$ & $\begin{array}{l}-0.44 \\
(2.82)\end{array}$ & $\begin{array}{l}-0.24 \\
(0.58)\end{array}$ & $\begin{array}{l}-0.21 \\
(0.40)\end{array}$ \\
\hline War-Prohibition $_{t-1}$ & & & $\begin{array}{l}-0.93 \\
(5.68)\end{array}$ & $\begin{array}{l}-0.72 \\
(3.07)\end{array}$ & $\begin{array}{c}-2.54 \\
(1.19)\end{array}$ & $\begin{array}{l}-1.18 \\
(0.79)\end{array}$ \\
\hline War-Prohibition $_{t-2}$ & & & & $\begin{array}{l}-0.84 \\
(2.93)\end{array}$ & & $\begin{array}{l}-2.74 \\
(0.83)\end{array}$ \\
\hline Impact of Prohibition & $\begin{array}{l}-2.58 \\
(.000)\end{array}$ & $\begin{array}{l}-2.29 \\
(.000)\end{array}$ & $\begin{array}{l}-1.04 \\
(.086)\end{array}$ & $\begin{array}{l}-0.47 \\
(.623)\end{array}$ & $\begin{array}{l}-1.23 \\
(.012)\end{array}$ & $\begin{array}{l}-0.84 \\
(.150)\end{array}$ \\
\hline $\mathrm{N}$ & 94 & 93 & 92 & 91 & 91 & 89 \\
\hline$R^{2}$ & .94 & .98 & .98 & .99 & .94 & .94 \\
\hline
\end{tabular}

Newey and West (1987) t-statistics in parentheses. 
Table 5

Impact of Prohibition and Other Factors, Various Specifications

\begin{tabular}{|c|c|c|c|c|c|c|c|c|c|c|}
\hline & OLS & OLS & OLS & OLS & OLS & OLS & OLS & OLS & OLS & OLS \\
\hline Early Prohibition & 1.88 & & & & & & & & & 0.04 \\
\hline Late Prohibition & -0.60 & & & & & & & & & 1.08 \\
\hline Enforcement of Prohibition & & -0.73 & & & & -1.56 & 12.70 & & 42.1 & 11.7 \\
\hline State-Level Prohibitions & & & -0.58 & & & & 0.09 & 4.96 & -0.25 & -0.62 \\
\hline Drug Prohibitions & & & & -0.93 & & & -0.10 & -3.82 & -0.40 & -0.35 \\
\hline Alcohol Taxes & & & & & 31.7 & & 36.9 & 27.1 & 35.9 & 36.6 \\
\hline Prohibition & & & -0.59 & -0.65 & 9.92 & 0.87 & & 9.17 & -0.17 & \\
\hline & IV & IV & IV & IV & IV & IV & IV & IV & IV & IV \\
\hline Early Prohibition & -1.31 & & & & & & & & & $\mathrm{NC}$ \\
\hline Late Prohibition & -0.90 & & & & & & & & & $\mathrm{NC}$ \\
\hline Enforcement of Prohibition & & -0.41 & & & & 1.94 & $\mathrm{NC}$ & & $\mathrm{NC}$ & $\mathrm{NC}$ \\
\hline State-Level Prohibitions & & & -0.26 & & & & $\mathrm{NC}$ & 1.96 & $\mathrm{NC}$ & $\mathrm{NC}$ \\
\hline Drug Prohibitions & & & & -0.97 & & & $\mathrm{NC}$ & -1.10 & $\mathrm{NC}$ & $\mathrm{NC}$ \\
\hline Alcohol Taxes & & & & & 3.59 & & $\mathrm{NC}$ & 6.49 & $\mathrm{NC}$ & $\mathrm{NC}$ \\
\hline Prohibition & & & -0.88 & -1.01 & 0.04 & -2.26 & & 1.40 & $\mathrm{NC}$ & \\
\hline
\end{tabular}

$\mathrm{NC}=$ not computed because estimated roots of equation are unstable. 
Table 1a

Regressions of Cirrhosis on Alcohol Consumption, 1900-1919

\begin{tabular}{|c|c|c|c|c|c|c|}
\hline & \multicolumn{3}{|c|}{ Age Variables Excluded } & \multicolumn{3}{|c|}{ Age Variables Included } \\
\hline Constant & $\begin{array}{l}10.57 \\
(6.11)\end{array}$ & $\begin{array}{r}1.78 \\
(0.67)\end{array}$ & $\begin{array}{c}5.75 \\
(1.98)\end{array}$ & $\begin{array}{c}1444.2 \\
(0.44)\end{array}$ & $\begin{array}{c}732.8 \\
(0.23)\end{array}$ & $\begin{array}{c}-1192.0 \\
(0.32)\end{array}$ \\
\hline Trend & $\begin{array}{l}-0.14 \\
(5.37)\end{array}$ & $\begin{array}{l}-0.08 \\
(4.01)\end{array}$ & $\begin{array}{l}-0.11 \\
(4.43)\end{array}$ & $\begin{array}{l}-3.69 \\
(0.36)\end{array}$ & $\begin{array}{l}-2.19 \\
(0.20)\end{array}$ & $\begin{array}{l}-4.47 \\
(0.37)\end{array}$ \\
\hline Alcohol & $\begin{array}{r}4.91 \\
(9.71)\end{array}$ & & $\begin{array}{c}2.59 \\
(2.26)\end{array}$ & $\begin{array}{c}2.05 \\
(2.03)\end{array}$ & & $\begin{array}{c}2.15 \\
(1.69)\end{array}$ \\
\hline Lagged Cirrhosis & & $\begin{array}{c}1.08 \\
(6.65)\end{array}$ & $\begin{array}{c}0.56 \\
(1.95)\end{array}$ & & $\begin{array}{c}0.01 \\
(0.03)\end{array}$ & $\begin{array}{l}-0.18 \\
(0.52)\end{array}$ \\
\hline Impact of Alcohol & $\begin{array}{r}4.91 \\
(.000)\end{array}$ & & $\begin{array}{c}5.89 \\
(.000)\end{array}$ & $\begin{array}{c}2.05 \\
(.042)\end{array}$ & & $\begin{array}{r}1.82 \\
(.009)\end{array}$ \\
\hline $\mathrm{N}$ & 20 & 19 & 19 & 20 & 19 & 19 \\
\hline$R^{2}$ & .91 & .93 & .96 & .98 & .97 & .98 \\
\hline
\end{tabular}

Newey and West (1987) t-statistics in parentheses. 
Table $1 \mathrm{~b}$

Regressions of Cirrhosis on Alcohol Consumption, 1934-1966

\begin{tabular}{|c|c|c|c|c|c|c|}
\hline & \multicolumn{3}{|c|}{ Age Variables Excluded } & \multicolumn{3}{|c|}{ Age Variables Included } \\
\hline Constant & $\begin{array}{l}-1.38 \\
(1.63)\end{array}$ & $\begin{array}{l}-0.91 \\
(1.51)\end{array}$ & $\begin{array}{l}-0.97 \\
(1.53)\end{array}$ & $\begin{array}{l}19.00 \\
(0.18)\end{array}$ & $\begin{array}{l}-4.21 \\
(0.05)\end{array}$ & $\begin{array}{r}6.59 \\
(0.07)\end{array}$ \\
\hline Trend & $\begin{array}{c}0.13 \\
(9.73)\end{array}$ & $\begin{array}{c}0.09 \\
(3.11)\end{array}$ & $\begin{array}{c}0.09 \\
(3.02)\end{array}$ & $\begin{array}{l}-1.04 \\
(1.06)\end{array}$ & $\begin{array}{c}1.66 \\
(1.12)\end{array}$ & $\begin{array}{c}1.42 \\
(0.83)\end{array}$ \\
\hline Alcohol & $\begin{array}{c}0.52 \\
(1.23)\end{array}$ & & $\begin{array}{c}0.31 \\
(0.79)\end{array}$ & $\begin{array}{r}0.89 \\
(1.00)\end{array}$ & & $\begin{array}{r}0.76 \\
(0.76)\end{array}$ \\
\hline Lagged Cirrhosis & & $\begin{array}{c}0.40 \\
(1.76)\end{array}$ & $\begin{array}{c}0.38 \\
(1.59)\end{array}$ & & $\begin{array}{l}-0.17 \\
(0.59)\end{array}$ & $\begin{array}{l}-0.13 \\
(0.43)\end{array}$ \\
\hline Impact of Alcohol & $\begin{array}{c}0.52 \\
(.218)\end{array}$ & 0.50 & $(.416)$ & $\begin{array}{r}0.89 \\
(.316)\end{array}$ & & $\begin{array}{c}0.67 \\
(.495)\end{array}$ \\
\hline $\mathrm{N}$ & 33 & 33 & 33 & 33 & 33 & 33 \\
\hline$R^{2}$ & .88 & .89 & .89 & .93 & .93 & .93 \\
\hline
\end{tabular}

Newey and West (1987) t-statistics in parentheses. 
Table 1c

Regressions of Cirrhosis on Alcohol Consumption, 1964-1993

\begin{tabular}{|c|c|c|c|c|c|c|}
\hline & \multicolumn{3}{|c|}{ Age Variables Excluded } & \multicolumn{3}{|c|}{ Age Variables Included } \\
\hline Constant & $\begin{array}{l}30.18 \\
(7.06)\end{array}$ & $\begin{array}{c}7.28 \\
(4.20)\end{array}$ & $\begin{array}{c}5.06 \\
(2.72)\end{array}$ & $\begin{array}{l}-51.4 \\
(2.06)\end{array}$ & $\begin{array}{l}-48.6 \\
(2.07)\end{array}$ & $\begin{array}{r}-46.79 \\
(1.93)\end{array}$ \\
\hline Trend & $\begin{array}{l}-0.24 \\
(7.57)\end{array}$ & $\begin{array}{l}-0.05 \\
(4.69)\end{array}$ & $\begin{array}{l}-0.02 \\
(1.66)\end{array}$ & $\begin{array}{r}0.47 \\
(6.45)\end{array}$ & $\begin{array}{c}0.51 \\
(7.35)\end{array}$ & $\begin{array}{r}0.56 \\
(5.60)\end{array}$ \\
\hline Alcohol & $\begin{array}{c}4.20 \\
(2.87)\end{array}$ & & $\begin{array}{l}-0.91 \\
(0.79)\end{array}$ & $\begin{array}{c}1.32 \\
(0.95)\end{array}$ & & $\begin{array}{c}1.74 \\
(1.07)\end{array}$ \\
\hline Lagged Cirrhosis & & $\begin{array}{r}0.86 \\
(17.0)\end{array}$ & $\begin{array}{c}0.95 \\
(15.5)\end{array}$ & & $\begin{array}{l}-0.05 \\
(0.23)\end{array}$ & $\begin{array}{l}-0.18 \\
(0.64)\end{array}$ \\
\hline Impact of Alcohol & $\begin{array}{r}4.20 \\
(.004)\end{array}$ & & $\begin{array}{l}-18.2 \\
(.504)\end{array}$ & $\begin{array}{r}1.32 \\
(.343)\end{array}$ & & $\begin{array}{c}1.47 \\
(.251)\end{array}$ \\
\hline $\mathrm{N}$ & 30 & 30 & 30 & 30 & 30 & 30 \\
\hline$R^{2}$ & .78 & .97 & .98 & .99 & .99 & .99 \\
\hline
\end{tabular}

Newey and West (1987) t-statistics in parentheses. 
Table 1d

Regressions of Cirrhosis on Beer Consumption, 1900-1993

\begin{tabular}{|c|c|c|c|c|c|c|}
\hline & \multicolumn{3}{|c|}{ Age Variables Excluded } & \multicolumn{3}{|c|}{ Age Variables Included } \\
\hline Constant & $\begin{array}{c}6.85 \\
(4.19)\end{array}$ & $\begin{array}{c}0.36 \\
(0.75)\end{array}$ & $\begin{array}{c}0.52 \\
(0.97)\end{array}$ & $\begin{array}{l}40.18 \\
(1.69)\end{array}$ & $\begin{array}{c}3.03 \\
(0.13)\end{array}$ & $\begin{array}{l}-6.27 \\
(0.30)\end{array}$ \\
\hline Trend & $\begin{array}{l}-0.02 \\
(1.21)\end{array}$ & $\begin{array}{c}0.00 \\
(0.00)\end{array}$ & $\begin{array}{c}0.00 \\
(0.59)\end{array}$ & $\begin{array}{l}-0.03 \\
(0.56)\end{array}$ & $\begin{array}{l}-0.10 \\
(2.16)\end{array}$ & $\begin{array}{l}-0.10 \\
(2.15)\end{array}$ \\
\hline Beer & $\begin{array}{c}0.34 \\
(4.00)\end{array}$ & & $\begin{array}{l}-0.03 \\
(1.07)\end{array}$ & $\begin{array}{c}0.30 \\
(4.55)\end{array}$ & & $\begin{array}{c}0.12 \\
(1.91)\end{array}$ \\
\hline Lagged Cirrhosis & & $\begin{array}{c}0.97 \\
(33.11)\end{array}$ & $\begin{array}{c}0.99 \\
(27.3)\end{array}$ & & $\begin{array}{c}0.86 \\
(5.21)\end{array}$ & $\begin{array}{c}0.68 \\
(3.81)\end{array}$ \\
\hline Impact of Beer & $\begin{array}{c}0.34 \\
(.000)\end{array}$ & & $\begin{array}{l}-5.67 \\
(.874)\end{array}$ & $\begin{array}{c}0.30 \\
(.000)\end{array}$ & & $\begin{array}{r}0.38 \\
(.025)\end{array}$ \\
\hline $\mathrm{N}$ & 80 & 79 & 79 & 80 & 79 & 79 \\
\hline$R^{2}$ & .25 & .93 & .94 & .94 & .96 & .96 \\
\hline
\end{tabular}

Newey and West (1987) t-statistics in parentheses. 
Table 1e

Regressions of Cirrhosis on Spirits Consumption, 1900-1993

\begin{tabular}{|c|c|c|c|c|c|c|}
\hline \multirow[b]{2}{*}{ Constant } & \multicolumn{3}{|c|}{ Age Variables Excluded } & \multicolumn{3}{|c|}{ Age Variables Included } \\
\hline & $\begin{array}{c}4.45 \\
(4.41)\end{array}$ & $\begin{array}{c}0.36 \\
(0.75)\end{array}$ & $\begin{array}{c}0.47 \\
(0.90)\end{array}$ & $\begin{array}{c}73.3 \\
(3.16)\end{array}$ & $\begin{array}{c}3.03 \\
(0.13)\end{array}$ & $\begin{array}{l}-7.83 \\
(0.39)\end{array}$ \\
\hline Trend & $\begin{array}{l}-0.02 \\
(3.51)\end{array}$ & $\begin{array}{c}0.00 \\
(0.00)\end{array}$ & $\begin{array}{l}-0.00 \\
(0.38)\end{array}$ & $\begin{array}{l}-0.02 \\
(0.23)\end{array}$ & $\begin{array}{l}-0.10 \\
(2.16)\end{array}$ & $\begin{array}{l}-0.10 \\
(2.02)\end{array}$ \\
\hline Spirits & $\begin{array}{c}6.67 \\
(9.08)\end{array}$ & & $\begin{array}{c}0.43 \\
(0.66)\end{array}$ & $\begin{array}{c}2.63 \\
(2.85)\end{array}$ & & $\begin{array}{c}1.25 \\
(1.98)\end{array}$ \\
\hline Lagged Cirrhosis & & $\begin{array}{c}0.97 \\
(33.11)\end{array}$ & $\begin{array}{c}0.92 \\
(11.5)\end{array}$ & & $\begin{array}{c}0.86 \\
(5.21)\end{array}$ & $\begin{array}{c}0.77 \\
(4.96)\end{array}$ \\
\hline Impact of Spirits & $\begin{array}{c}6.67 \\
(.000)\end{array}$ & & $\begin{array}{r}5.23 \\
(.163)\end{array}$ & $\begin{array}{c}2.63 \\
(.004)\end{array}$ & & $\begin{array}{r}5.39 \\
(.088)\end{array}$ \\
\hline $\mathrm{N}$ & 80 & 79 & 79 & 80 & 79 & 79 \\
\hline$R^{2}$ & .74 & .93 & .94 & .92 & .96 & .96 \\
\hline
\end{tabular}

Newey and West (1987) t-statistics in parentheses. 
Table 1f

Regressions of Cirrhosis on Wine Consumption, 1900-1993

\begin{tabular}{|c|c|c|c|c|c|c|}
\hline & \multicolumn{3}{|c|}{ Age Variables Excluded } & \multicolumn{3}{|c|}{ Age Variables Includec } \\
\hline Constant & $\begin{array}{l}12.71 \\
(12.7)\end{array}$ & $\begin{array}{c}0.36 \\
(0.75)\end{array}$ & $\begin{array}{l}-0.35 \\
(0.62)\end{array}$ & $\begin{array}{l}116.1 \\
(5.57)\end{array}$ & $\begin{array}{c}3.03 \\
(0.13)\end{array}$ & $\begin{array}{c}5.63 \\
(0.26)\end{array}$ \\
\hline Trend & $\begin{array}{l}-0.05 \\
(1.97)\end{array}$ & $\begin{array}{c}0.00 \\
(0.00)\end{array}$ & $\begin{array}{c}0.01 \\
(1.98)\end{array}$ & $\begin{array}{l}-0.01 \\
(0.13)\end{array}$ & $\begin{array}{l}-0.10 \\
(2.16)\end{array}$ & $\begin{array}{l}-0.10 \\
(2.34)\end{array}$ \\
\hline Wine & $\begin{array}{c}2.83 \\
(2.18)\end{array}$ & & $\begin{array}{l}-0.61 \\
(3.13)\end{array}$ & $\begin{array}{c}0.57 \\
(0.47)\end{array}$ & & $\begin{array}{l}-0.41 \\
(0.52)\end{array}$ \\
\hline Lagged Cirrhosis & & $\begin{array}{c}0.97 \\
(33.11)\end{array}$ & $\begin{array}{c}1.00 \\
(32.9)\end{array}$ & & $\begin{array}{c}0.86 \\
(5.21)\end{array}$ & $\begin{array}{c}0.86 \\
(4.96)\end{array}$ \\
\hline Impact of Wine & $\begin{array}{r}2.83 \\
(.029)\end{array}$ & & $\begin{array}{l}101.2 \\
(.804)\end{array}$ & $\begin{array}{c}0.57 \\
(.637)\end{array}$ & & $\begin{array}{l}-3.04 \\
(.722)\end{array}$ \\
\hline $\mathrm{N}$ & 80 & 79 & 79 & 80 & 79 & 79 \\
\hline$R^{2}$ & .16 & .93 & .94 & .91 & .96 & .96 \\
\hline
\end{tabular}

Newey and West (1987) t-statistics in parentheses. 


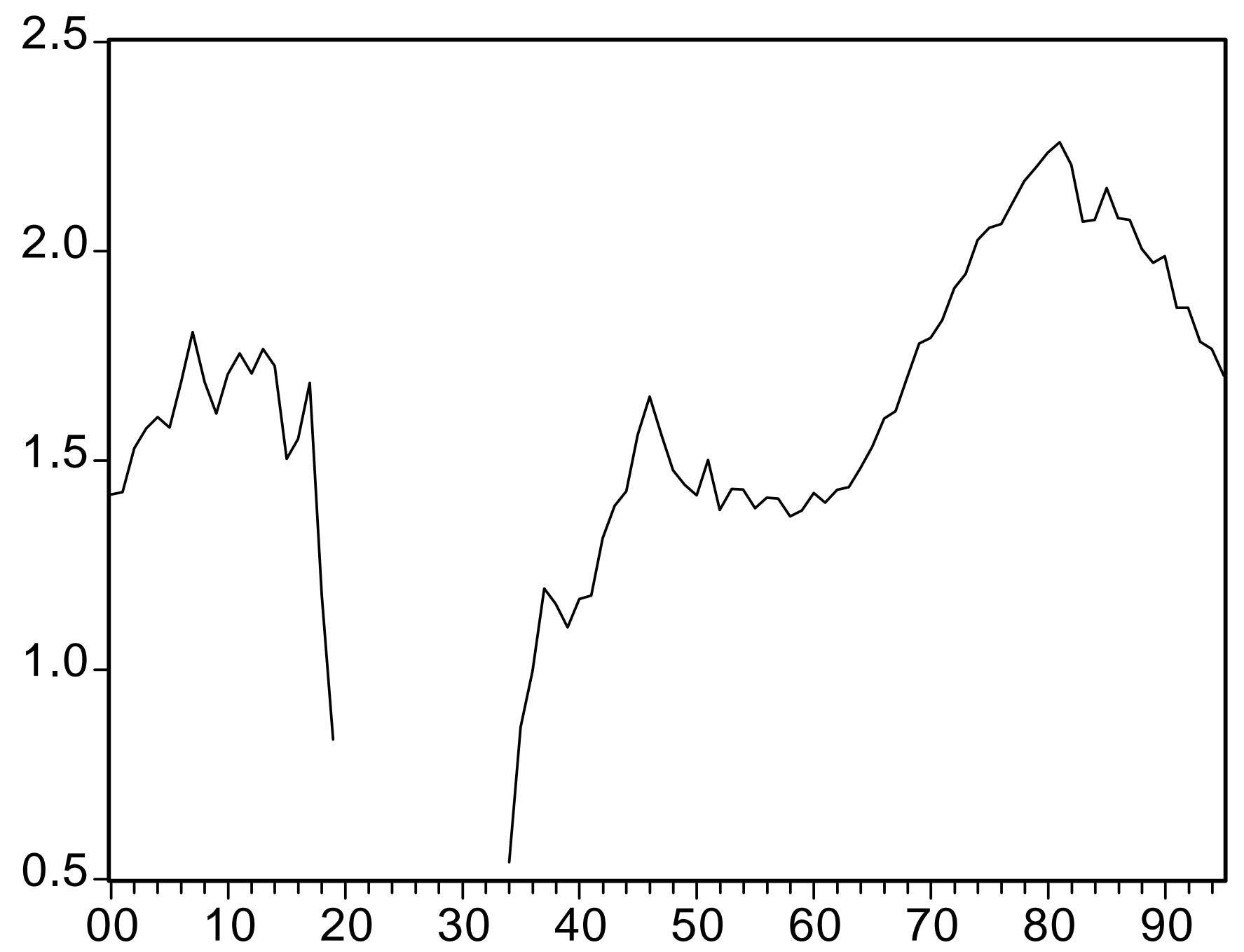

Figure 1: Alcohol Consumption Per Capita, 1900-1993 Gallons of Pure Alcohol 


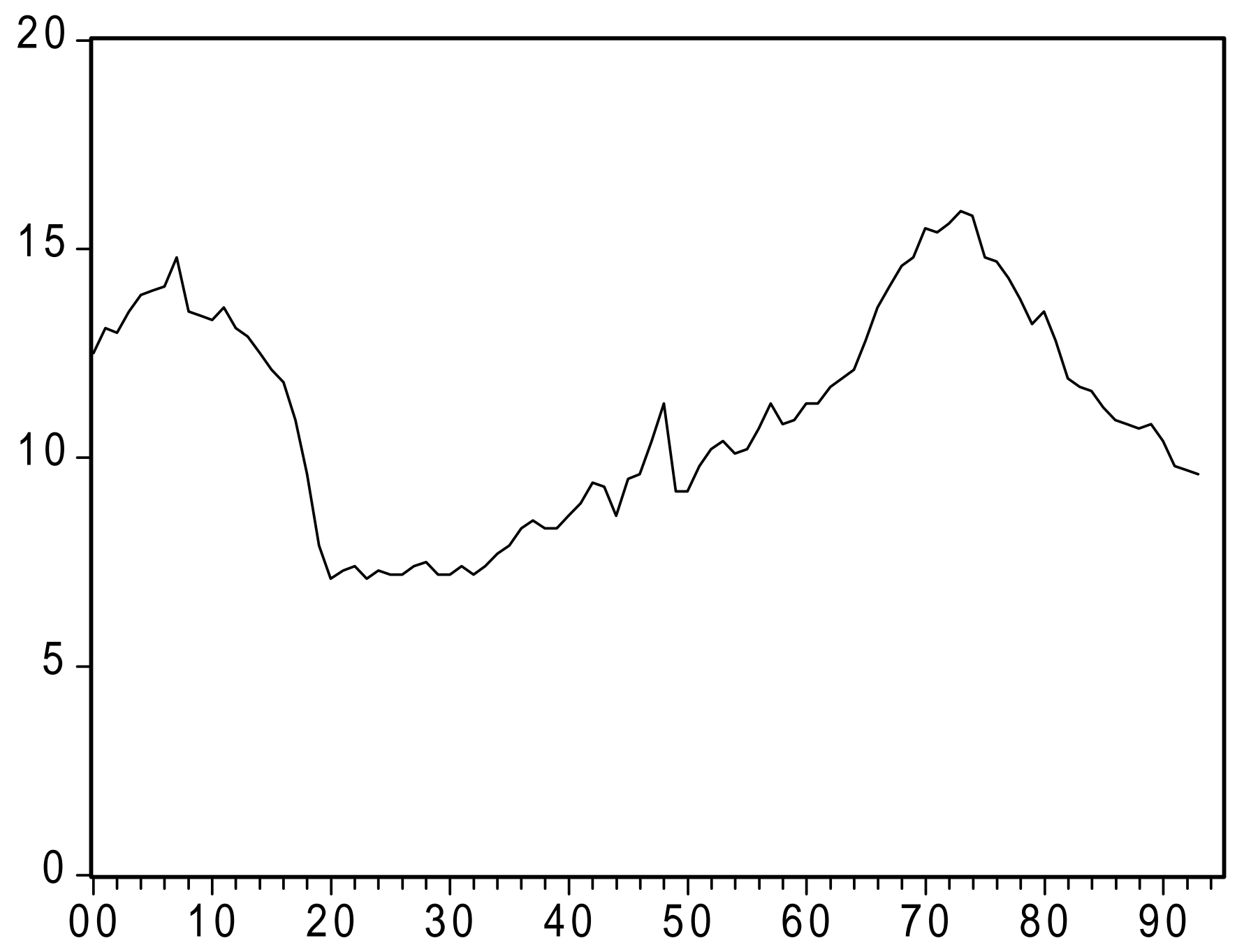

Figure 2: Cirrhosis Death Rate, 1900-1993 Deaths per 100,000 Population 